\title{
Representaciones del cuerpo e identidad de género y étnica en la población indígena del norte de Chile ${ }^{1}$
}

VIVIAN GaVILÁN V. ${ }^{2}$

\begin{abstract}
RESUMEN
Este artículo expone cómo las representaciones del cuerpo se relacionan con las identidades étnicas y de género de la población de habla aymara en el Norte Grande de Chile. Con un enfoque fenomenológico que considera y explora la subjetividad del actor social indígena, se intenta conocer la manera en que opera la identidad simbólica de este grupo social. En particular, se explora cómo las partes del cuerpo humano, sus funciones y los sentidos que tienen para los actores los usos del cuerpo, pueden formar parte de la identidad social de esta población culturalmente distinguible en la región de Tarapacá.
\end{abstract}

Palabras claves: aymara - identidad de género - identidad étnica - representaciones del cuerpo.

\begin{abstract}
This paper presents the ways in which representations of the body relate to ethnic and gender identities of the aymara-speaking population in the north of Chile. Taking a phenomenological approach that considers and explores the subjectivity of the indigenous social actor, the study seeks to know the manner in which the symbolic identity of this social group operates. Specifically, it explores how human body parts, their functions, as well as what social actors think of them, can be part of the social identity of a culturally distinguishable population in the region of Tarapacá.
\end{abstract}

Key words: aymara - gender identity - ethnic identity representations of the body.

Recibido: enero 2005. Aceptado: julio 2005.

\section{Introducción}

En una de sus últimas publicaciones Marta Lamas (2002) afirma que no es común en la antropología

1 Este trabajo es parte de los resultados del Proyecto FONDECYT 1020507: "Identidades sociales en Tarapacá. Conflictos interétnicos y nacionalismos en la sociedad regional contemporánea".

2 Centro de Investigaciones para el Desarrollo del Hombre en el Desierto (CIHDE), Universidad Arturo Prat. Av. Arturo Prat 2120, Iquique, CHILE. Email: vivian.gavilan@unap.c1 interrogarse sobre qué ocurre con las formas particulares que el cuerpo, construido culturalmente, toma en el imaginario de las personas. El sicoanálisis sería la disciplina que ha explorado en cómo cada sujeto elabora en su inconsciente la diferencia sexual. Propone, entonces, que la identidad "social" de las personas como "mujeres" u "hombres" - la identidad de género-y la identidad sexual estructurada en el inconsciente no son lo mismo. Sin embargo, se suele subsumir una dentro de la otra.

A esta constatación yo agregaría que la antropología se ha interesado poco en el estudio comparativo de las representaciones del cuerpo. Ello, a pesar de las importantes contribuciones pioneras de Mauss y, posteriormente, de Turner y Douglas, quienes han contribuido de manera central a situar este tema como objeto de estudio (p.e., Mauss 1991; Turner 1989 y 1994; Douglas 1979). Y en las últimas décadas no se pueden dejar de mencionar los notables aportes de Foucault (1980 y 1995) y Bourdieu (1991) para recuperar al cuerpo en la teoría social.

Como dato biológico, el Homo sapiens, es hoy universal; pero, también sabemos que el cuerpo humano ha variado a través de la historia tanto como sus representaciones. Si pensamos que estas representaciones son elaboraciones simbólicas y éstas, en tanto constituyen una actividad humana, están sometidas a transformaciones y si consideramos que los grupos sociales se hallan en permanente interacción, tenemos que asumir que los intercambios en este ámbito pueden ser muchos y múltiples. En consecuencia, así como existiría una relación arbitraria entre el dato biológico y su simbolización, no existiría una esencia en el cuerpo que determine su representación. Lo que si existiría es: un determinado grupo social con una determinada convicción acerca de una esencia del cuerpo humano (y sus diferencias) en un determinado tiempo, que sostiene la elaboración de un determinado tipo de subjetividad. 
Y si consideramos que la identidad constituye la dimensión subjetiva que los actores tienen de sí mismos y de los otros, podemos afirmar que el estudio de las representaciones sociales del cuerpo humano elaboradas por un grupo social específico nos facilitará el camino para investigar cómo éstas se relacionan con la identidad social de ese grupo.

Si formulamos estas aseveraciones bajo la forma de hipótesis, podemos averiguar cómo se comportan, eligiendo un grupo social entre otros: la población indígena cuya lengua es el aymara y que reside en el norte de chile. Este constituye uno de varios grupos étnicos en la región de Tarapacá. Podemos explorar, por ejemplo, cómo las partes del cuerpo humano, sus funciones y los sentidos que tienen para los actores pueden formar parte de un sistema de representaciones que define al sí mismo y a los grupos a los cuales pertenece, así como también a los otros y sus respectivos grupos. Este es el propósito del presente trabajo. Intenta abordar la dimensión subjetiva de la identidad de este grupo étnico. A partir de un corpus de datos referidos al cuerpo recopilado en un trabajo etnográfico, entrevistas (en el campo y la ciudad) y en fuentes secundarias, se busca comprender cómo la etnicidad y el género se manifiestan en la identidad social de las personas.

\section{Uno: El sujeto étnico}

¿A qué nos referimos cuando hablamos de sujeto étnico? El concepto de sujeto étnico se refiere a la persona (o grupo) que se adscribe a un grupo social diferenciado culturalmente de otros. La población de origen aymara en Tarapacá constituye un grupo étnico, pues se trata de una colectividad culturalmente distinguible, tanto por la población no indígena como también por ellos mismos. La sociedad regional identifica a "los aymara" como un todo, un grupo indígena diferente no sólo en términos culturales, sino también raciales. Esta distintividad constituiría, en palabras de Oommen (1994), el resultado de un largo proceso histórico, iniciado en el siglo XVI y prolongado hasta nuestros días. Se trataría de un proceso por el que ciertas colectividades son definidas y percibidas como foráneas (outsiders), es decir, como extranjeras en sus propios territorios.

Los trabajos que abordan la cuestión de los procesos de identidad étnica en la región han realizado grandes aportes para la comprensión de la realidad social del presente en el norte chileno (Chipana 1986; Grebe 1986; González y Gavilán 1992; Tudela 1992; van Kessel 1996; Gundermann 2001 y $2001 \mathrm{Ms}$, entre otros). No obstante, son escasos los estudios acerca de la subjetividad del actor social indígena, dimensión central de la identidad étnica en la región.

Se podría decir que los enfoques aplicados al conocimiento de la población indígena regional se pueden ordenar o simplificar dentro del esquema clásico: primordialismo/constructivismo. Entre los primeros se hallan los trabajos de van Kessel y seguidores, cuya perspectiva se orienta a dilucidar la "esencia" del "mundo andino". 3

Esta perspectiva considera la idea de la persistencia de una matriz cultural precolombina opuesta a la occidental, que ha sido transformada causando pérdidas de envergadura, al punto de la desintegración. No obstante, el autor sostiene que a pesar del éxodo de la población aymara a la ciudad y su integración cultural a la sociedad urbana, hay brotes inesperados de una conciencia renovada de identidad aymara, tanto en la ciudad como en el campo:

"Su identidad étnica ya no aparece tan despreciada y puede ser provechosa. Por otra parte, el peligro y la angustia de perderla parecen despertar un movimiento renacentista entre los propios aymara. Prueba de ello son las nuevas organizaciones que nacieron en el campo y la ciudad. Otros indicios del mismo proceso son por ejemplo la participación aymara en el proceso de la nueva Ley Indígena. Podría argumentarse que por la política gubernamental y la acción de la sociedad circundante, la comunidad aymara y sus estructuras sociales fueron definitivamente desmanteladas sin embargo, no estamos frente a una nivelación acabada ni a la chilenización pura y simple, sino frente a múltiples brotes de un

\footnotetext{
3 Aunque con algunas diferencias, autores como Tudela, Grebe y Chipana podrían inscribirse en esta línea, en la medida en que al estudiar el cambio social se parte del supuesto de un antes no contaminado. Se tiende a olvidar la permanente relación de intercambios culturales que se han producido a través de la historia y de la posición subordinada de las comunidades de origen indígena; se olvida que nos situamos en un contexto de larga tradición colonialista en el cual las personas no han sido un ente pasivo, sino sujetos activos de los procesos sociales.
} 
fenómeno de reetnificación de los aymara de Chile (estratégicamente)" (van Kessel 1996).

El autor no se pregunta por qué esta posible identidad estratégica se elabora en determinado contexto. No cabe esta pregunta en una visión que postula la continuidad de una identidad étnica fundamental y de larga duración, a pesar de las transformaciones.

Por la otra, hallamos una visión más historicista que considera a los aymara como un grupo social, entre otros, afectado por el desarrollo sociohistórico regional. Gundermann, por ejemplo, propone que la comunidad aymara debería entenderse en el marco de un proceso histórico cuyas rupturas, impuestas por el sistema colonial y por la instauración de una modernidad latinoamericana, dan como resultado nuevas formas que muestran tanto elementos de continuidad como de transformación. En este sentido, el autor sugiere que la persistencia debe verse como continuidad transformada de las instituciones andinas. Agrega, además, que la continuidad se situaría en el plano de las representaciones sociales y en la recuperación de prácticas sociales (p.e., relaciones de parentesco y compadrazgo) que contribuyen a la incorporación aymara a las corrientes regionales de la modernidad (Gundermann 2001 y 2001 Ms).

González (1997 y 2000), por su parte, sugiere que las transformaciones de pérdida y adopción de patrones y elementos culturales se relacionan con los conceptos de nacionalismo y globalización. Los aymara de Tarapacá tuvieron que acomodarse a una nueva nacionalidad para pasar de peruanos a chilenos. Bajo la égida chilena y en un contexto de ocupación, pasa a ser el símbolo de la extranjeridad sometida y del atraso o barbarie (india) de los vencidos. El proyecto chilenizador habría significado el desencadenamiento de un proceso de pérdida cultural y aculturación por imposición e imitación. Pese a los procesos reseñados, señala que los aymara continúan siendo un grupo particular y contrastante al interior de la región. Su cultura se ha transformado, pero mantiene espacios que aseguran su reproducción.

Talvez y como indican Giménez (2000a) y otros autores (Oommen 1994; D’Andrea 2000), no serían visiones contradictorias. Tanto la visión de tendencia primordialista como la constructivista aportan elementos para el conocimiento de la pobla- ción indígena. Los primeros, preocupados por la continuidad, contribuyen a dilucidar su particularidad y, los segundos, ponen énfasis en el cambio y en la necesidad de entenderla como parte de los procesos sociales regionales; contexto sin el cual es imposible comprender el presente. Me parece necesario, sin embargo, distinguir entre los argumentos de los actores sociales y los del observador. Una cosa es que los aymara asuman ciertas características culturales fundamentales como pueblo, basadas en cualidades primordiales (o que los no indígenas les asignen), y otra muy diferente los resultados reales de los procesos sociohistóricos que han intervenido en la arquitectura de la identidad social y, dentro de ésta, en la identidad étnica. Habría que recordar que:

"cuando se rastrea la historia de un grupo étnico a lo largo del tiempo, no se está rastreando simultáneamente, en el mismo sentido, la historia de una 'cultura'; los elementos de la cultura actual de ese grupo étnico no han emanado del conjunto particular que constituyó la cultura del grupo en un momento previo, mientras que el grupo tiene una existencia organizativa continua, con fronteras (criterios de pertenencia) que han precisado una unidad continua" (Barth, cit. en Keyes 2000).

Olvidar esta cuestión impone serias limitaciones para comprender las complejas dinámicas actuales en las que se desenvuelve el pueblo aymara.

La visión que sitúa al pueblo indígena dentro de la historia regional, si bien permite entender su situación actual en relación a otros grupos o al Estado, presenta de igual modo algunas debilidades. Por un lado, persiste la tendencia a oponer tradición y modernización y, por el otro, se echa de menos al sujeto y su agencia. El punto de vista subjetivo de los propios grupos en cuestión es importante, pues carece de sentido hablar de la identidad étnica en general. La identidad es siempre un problema concreto y un enigma que debe resolverse para cada grupo o colectividad en particular desde la perspectiva de sus miembros (Giménez 2000a).

Si asumimos que la tradición no constituye por sí misma la antítesis de la modernización, podríamos evitar el pensamiento dualista, reductor de la complejidad (Giménez 2000b). Los datos entregados por la mayoría de los investigadores regionales nos hablan de un actor indígena activo en el proceso de modernización, pues la tradición se define esen- 
cialmente por conferir al pasado una autoridad trascendente para regular el presente (Hervieu-Léger 1993: 126-127), y las bases de esta autoridad no es la antigüedad sino "la convicción" de que la continuidad con el pasado es capaz de incorporar incluso las innovaciones y reinterpretaciones que exige el presente. Por lo tanto, la tradición es una noción dinámica compatible, en principio, con el cambio, la modernización y el desarrollo (D'Andrea 2000).

La población indígena ha sido conformada como un grupo étnico (minoritario y marginalizado) en el territorio que ocupaba, por otra colectividad dominante y que hasta hace poco se negaba a reconocer o desvirtuaba sus vínculos morales y simbólicos con dicho territorio.

A lo dicho por otros investigadores yo quisiera agregar que la población aymara en la región no sólo constituye un grupo étnico, sino también un grupo racial para la población no indígena, y para ella misma. Aunque se base en una distinción biológica falaz, resultante de la confusión entre el genotipo y el fenotipo, la raza y el color de la piel, al tratarse de una noción social que configura la actitud y el comportamiento humano, es una variable pertinente desde el punto de vista sociológico (Oommen 1994: 101). La persistencia de estereotipos entre la población no indígena es un argumento suficiente para distinguir la dimensión étnica de la racial, y no encerrar raza en etnia.

Veamos cómo lo expresa un importante dirigente indígena regional a inicios de 2004:

"Ser aymara se manifiesta desde la misma condición de nuestra forma de ser como personas, con todas nuestras características biológicas, físicas ¿cierto? Usted me ve a mí y me identifica como aymara por mis rasgos, por la piel y por todo eso, y eso es replicable en la ciudad en todos los lugares. Si usted entra a una oficina de impuestos internos me ve a mí, ya tiene conocimiento que soy aymara o soy indígena. No es así?". ${ }^{4}$

Siguiendo a Oommen, podemos ver que la distinción entre etnia y raza en la región es clave, pues nos permitiría observar cómo la población étnicamente diferente puede transformarse en el

4 Fragmento de entrevista de Antonio Mamani, en Maluenda y Valenzuela (2004) curso de un período mediante un proceso de asimilación e incorporación cultural (a través de mecanismos tales como la conversión religiosa, la sustitución de la lengua materna por otra adquirida o la adopción de un nuevo estilo de vida). Es el caso, por ejemplo, de la población europea que vino durante la época del salitre. Sin embargo, quienes son de raza diferente no pueden transformarse, incluso cuando el mestizaje es aceptado y aplicado sistemáticamente como ideología y sistema de valores. Al mismo tiempo, es posible la existencia de grupos étnicos dentro del mismo tipo físico o de la misma raza, como ocurría en tiempos prehispánicos. ${ }^{5}$ Así, todos los que pertenecen a la misma raza talvez no profesen la misma religión, hablen el mismo idioma o tengan el mismo estilo de vida. ${ }^{6}$

Como dice este autor, el origen étnico puede manifestarse únicamente en determinadas situaciones de interacción; pero esta relación se da en un contexto de poder en el que la posición que ocupa la etnia aymara en la región es claramente subordinada. Para recuperar esta dimensión vale la pena distinguir la etnia como símbolo y la etnia como instrumento. $\mathrm{La}$ primera se refiere básicamente a la construcción y mantenimiento de límites socioculturales, esto es, a la búsqueda de una identidad. En cambio la etnia como instrumento apunta a combatir la desigualdad material. Por lo tanto, la etnia que busca una identidad sería cualitativamente distinta de la que lucha en pro de la igualdad (Oommen 1994).

Con estos antecedentes podríamos dar respuesta a la pregunta formulada. Un sujeto étnico aymara en la Región de Tarapacá (definido por ellos mismos y por la población no indígena) es aquel que es identificado con un color de piel oscura, cabello oscuro y

5 Es posible que hasta hoy se puedan constatar diferentes grupos étnicos al interior de la población indígena, tales como aymara, quechua y chipaya. Asimismo, es probable que si investigamos al sujeto étnico en esta zona podamos encontrar que los grupos locales constituyan en verdad grupos étnicos como en Isluga, Cariquima, Chiapa.

6 Oommen indica que "la raza es un hecho biológico, pero el racismo es una ideología y una práctica basada en la supuesta superioridad de algunas razas, tradicionalmente sólo la blanca pero últimamente también la amarilla. La etnicidad es esencialmente un asunto cultural y el hecho de ser culturalmente diferente no entraña superioridad ni inferioridad. Sin embargo, no es inusitado que ciertas colectividades culturales se definan como culturalmente superiores y consideren inferior la cultura de otros" (Oommen 1994: 102). 
liso, con nariz prominente, con una forma particular de vestir y peinarse, que gusta de un tipo de música específico, que tienden a casarse al interior del propio grupo con relaciones sociales al interior del hogar y un tipo de religiosidad, también distinguibles. Uno de los aspectos que resalta como vecino es su poca disposición a participar socialmente en las organizaciones barriales con los no indígenas y su capacidad para el comercio y el ahorro. Por otra parte, se le considera un conocedor del territorio y un excelente campesino. Exceptuando esto último, todos son atributos negativos los que aún en la actualidad se sintetizan en la categoría "indio". 7

La población de origen indígena de habla aymara del altiplano se refiere a los no indígenas como q'ara. Esta categoría lingüística es registrada por Bertonio (1984 [1612]) de la siguiente manera: "dícese de todo lo que es pelado, como la cabeza, cerros, llanos y si es piedra o peña hanccara". Las siguientes expresiones nos informan de su sentido y aplicaciones:

Kara Ppekeñani $=$ calvo

Karalaccampu $=$ cielo raso

Karaisi $=$ vestido sin pelo

Karakhatatha $=$ estar sin gente la plaza

Kara $=$ de un solo color

Kara puntas $=$ de rostro blancas

Asimismo, la expresión karakhatha significa pelarse, quedar sin nada (Bertonio 1984 [1612]: 357). De aquí emerge el término q'ara para referirse al "otro": el español invasor. ¿Por qué fue ésta la palabra seleccionada? Esta pregunta es importante aquí no por su respuesta literal, sino por lo que implica en términos de las representaciones que el indígena de habla aymara hizo y hace del "otro" no indio. Como toda expresión lingüística, sus significados han variado a través del tiempo. El seguimiento de esta evolución es importante, pues constituye un dato relevante para rescatar precisamente esos significados.

Chipana (1986: 256) nos dice que en la actualidad q'ara es el término que designa a una persona no india, ladino, blanco, refinado, ajeno a los andinos, condición de extraño o ignorante en la cultura

\footnotetext{
7 Estas características corresponderían tanto a la autopercepción de los aymara como a la percepción que de ellos tienen los no indígenas.
}

aymara. Indica que q'arakiptaña es la forma verbal que se usa para referirse a aquel que quiere imitar al q'ara. Es interesante también reconocer otra derivación de esta raíz como es la palabra q'araxtaña que significa empobrecerse, pero no en el sentido de bienes materiales sino de cultura: de normas y valores. Justamente el término q'ara significa pelado en el sentido de sin nada, que no tiene parientes. ${ }^{8}$ q'ara no es precisamente extraño o extranjero, pues esta idea se expresa en la palabra maysa jaqi.

Así como la categoría "indio" contiene la carga de un estigma y subsume etnia y raza, q'ara tiende a contener ciertos aspectos negativos, que resume también ambas dimensiones. Esto aparece con mayor claridad entre los dirigentes indígenas que, para enfrentar el estigma y superar la descalificación y subalternidad, han seguido la consigna "el indio es bello". En términos culturales la distinción que hace la población indígena respecto del q'ara, puede hallarse en las actitudes, opiniones y percepciones respecto de su forma de vida: es despilfarrador (no ahorra), es irrepestuoso con el buen comportamiento del ser humano, es débil para enfrentar el clima y las exigencias del medio ambiente de la región. Cuando se habla del buen o mal comportamiento se refieren a no seguir su propio sistema normativo. Así, situaciones tales como, la separación matrimonial, el respeto por el marido o la esposa, el respeto por los valores asociados al ciclo vital, el valor al trabajo, de la reciprocidad, entre otros, pueden dar pie a la descalificación, lo que puede derivar en la designación de anuq'ara o perro, como opuesto de jaqi (persona).

Entre los componentes culturales básicos de la representación social que tiene de sí mismo este grupo étnico se hallan aspectos tales como una tradición archivada en la memoria colectiva, que remite a antepasados comunes y que registra el trauma de la colonización; la reivindicación de sus territorios ancestrales como lugares de anclaje de esta memoria y referente simbólico de su identidad social; la valoración del lenguaje, no sólo como medio de comunicación intragrupal, sino como archivo vivo de su visión del mundo y símbolo distintivo de su identidad cultural y su religiosidad. ${ }^{9}$

8 Referencias entregadas por el profesor de lengua aymara, Elías Ticona.

9 La identificación de estos aspectos se basaron en Giménez 2000a. 
Es esta tradición la que se actualiza en la cosmovisión, en la elaboración de la historia social, en los rituales, en las prácticas productivas, en la salud y en la enfermedad, entre otros aspectos que los distinguen del Q'ara. Por lo tanto, las identidades de etnia y género se comprenden dentro de esta tradición. Serán las representaciones del cuerpo humano y sus diferencias las que constituirán la base sobre la cual se erigen las identidades sociales y sexuales.

\section{Dos: La historia local y la analogía del cuerpo. Las representaciones del cuerpo en la historia local}

"Toda clasificación implica un orden jerárquico, del que ni el mundo sensible ni nuestra conciencia nos ofrecen modelo alguno. El esquema de la clasificación no es un producto espontáneo del entendimiento abstracto, sino que resulta de una elaboración en la cual han entrado todo tipo de elementos extraños" (Durkheim y Mauss 1991 [1903]: 17).

Podemos partir diciendo que el cuerpo habla en la medida en que nos informa sobre la identidad y la personalidad de las personas: sobre el sexo, la edad, el origen étnico o social, la salud, etc. El cuerpo presta sus formas, sus funciones y sus estados a conceptos que a la vez ilustra y designa. Así, existen analogías corporales, relaciones del cuerpo y el mundo, hay un tipo de conocimiento del cuerpo y de sus funciones (Guiraud 2001 [1980]).

Durante las primeras décadas del siglo XX, Marcel Mauss insistía en la mediación de la cultura en la producción del cuerpo. Postuló que las "técnicas del cuerpo",

"el modo en que de sociedad en sociedad los seres humanos saben cómo usar sus cuerpos son un medio importante para la socialización de los individuos en la cultura. A través de éstas, un individuo llega a conocer una cultura y a vivir en ella" (Mauss 1973: 70 cit. en García 2004).

Según Mauss, el modo en que los hombres y las mujeres llegan a usar sus cuerpos es diferente, puesto que las técnicas corporales tienen género. Hombres y mujeres aprenden a caminar, a hablar, a correr, a luchar de forma diferente.

Douglas también ha reconocido el cuerpo como un objeto natural moldeado por las fuerzas sociales.
Para esta antropóloga existen dos cuerpos. El cuerpo físico y el cuerpo social, y afirma que éste último restringe el modo en que se percibe el cuerpo físico (Douglas 1988: 93, cit. en A. Martínez 2004). Las propiedades fisiológicas del cuerpo son, pues, el punto de partida para la cultura que hace de mediadora y las traduce en símbolos significativos en un sistema de símbolos naturales. Esto significa que el cuerpo es un medio de expresión altamente restringido, puesto que está mediatizado por la cultura y expresa la presión social que tiene que soportar.

El sistema de creencias aymara parece confirmar estas tesis. La organización social y los procesos culturales son modelados a imagen y semejanza de los procesos biológicos, y éstos se piensan de acuerdo a ideas articuladas a la cosmovisión y religiosidad. Relaciones isomorfas entre cuerpo y sociedad se observan en la concepción del territorio en tanto organismo animal, espacio geográfico (o cuerpo) determinado por las divinidades y el recuerdo del Inka.

Veamos, en palabras de los protagonistas, cómo el cuerpo es comprendido y significado. El primer testimonio forma parte de una entrevista aplicada por una joven aymara a un tío abuelo (Q.E.P.D); el segundo, una entrevista colectiva aplicada también por la misma joven a sus parientes. Ambas buscaban comprender la religiosidad actual. En español aymarizado, el abuelo expresa su propia interpretación de la historia indígena en la que el cuerpo sirve para representar al Estado inca:

“Otro no pu', otra forma, vilancha, ese de Inka; este la misa cualquier compadre, comadres, esa es otra cosa. Ese no pu', está la virgen no más. Ese no pu', evangélico dice el diablo, puro malo, diablo. No, no es diablo, porque diablo es inocente, porque diablo es otra forma, es otro. Porque el llamo dice, no? el llamo no se formó del dios ni padre, es inca, como nació el piedra, en cerro, el Inka hace nacimiento nació del llamo. Eso claro, porque nació del Inka, su nacimiento, ahí el Señor le bendició... todo levantó esta tierra, por eso tres mil año tiene que cumplir, ahí vamos a ver necesitado los vicios, ahora no 2500 años, ejercito de salvación, yo les lei pero ahí dice ah... Por eso hay que florear llamito, porque el dios que marcan por eso que florean, por el Pachamama, el Inka mallku, Inka t'allá está viendo ... el Inka hace el llamo, no la gente, el dios, no, eso es de Inka. Uno le enco- 
mienda, por eso challar, eso dicimos, esos otros dicen diablo, aviador, dicen diablo diablo diablo... No. Hay que dar bendición, esta tierra todo comimos, todas las plantas quinuas, papas, arroz todo comimos... Inka, todo el cerro, su hijo se nació del piedra, por eso tenía el Inka, por el español lo mataron esos, porque saben de esos tiene oro, metales tiene, de ahí lo mataron, el cuerpo, de ahí el Perú... ahora está manteniendo el Perú? ... el Inka, eso sabemos, es como un dios, que vale como un dios padre, el Inka, por eso estamos viviendo pobres acá, así no antes, seriamos ricos mismos."

Aquí aparecen varios elementos que configuran la identidad étnica: el pueblo ganadero, vive gracias a su ganado (llamas y alpacas) que sólo es manejado por la población indígena y que existe gracias al Inka, quien nació de la piedra en el cerro. El Inka que fue vencido y su cuerpo destrozado en tres partes, volverá a nacer para restaurar el orden perdido.

El mito del retorno, aquel que representa al Estado inca como un cuerpo humano que renacerá, es interpretado por los abuelos en términos territoriales. La cabeza, correspondería al actual Perú, otra zona intermedia (Bolivia) y las piernas la zona sur altiplano chileno y empobrecido. Recordemos que Garcilaso de la Vega (cit. en Bastien 1996), nos dice que la solidaridad del Imperio inca se hallaba en su parecido a un cuerpo humano.

Las montañas forman parte central de la mitología y son el lugar privilegiado para los rituales propiciatorios. Estas son representadas como antepasados o achachilas.

“Mujer: Por ejemplo acá en Kiñuta decían Sojay Mallko, Escarwaya T'alla. Hay dos cerritos pues, de wanka al frente hay cerro más abajo hay un cerro p'al lao de Kiñuta.

Hombre: Si tu miras ese cerro tiene cara de gente pue', Escarwaya. Usted le miras de Kiñita, es un hombre excelente.

Mujer: Wanapa también ese norte, tiene brazo codo, pata, para delante cara mismo con su arito, cara larguito, cara de india, larguito.

Mujer: Ahí, así es pues.

Hombre: Cara de Inka...

Mujer: Claro inca son esos pues, antes andaban en sus cerros, ese Wanapa ha venido de allá, de Bolivia ha venido dice pues. Por eso dice que estaba enamorado de los cerros de Sabaya de Cawarraya.
Hombre: Incluso el Wanapa de otro Sabaya...

Mujer: Le echaron con sartenejo el Sajama. Después el Sabaya se enamoró, después Wanapa se arrancó, dice que estaba siguiendo, de ahí hondeó. Wanapa le hondeó. Esos cerritos chicos son los hijos de Wanapa. Con dos guaguas ha venido Wanapa, Wanapa chico, el otro está allá al otro lado donde esta pina pue', con ese dos hijos.

Mujer: Ese se vino siguiendo al Sillajuaya.

Mujer: No, Wanapa es muy jodio por eso se arrancó pu', y se fue a la pampa.

Mujer: ¿Su marido es Sillajuaya?

Mujer: No sabemos, Sillajuaya será pues.

F: Sillajuaya ..., cuento de abuelo.

Hombre: Por eso hablaba que antiguamente el zorro se convertía de día gente, de noche es zorro, lagarto igual.

Mujer: En la noche se convertía en gente, al revés."

Los cuentos y leyendas nos hablan de cerros femeninos y masculinos, abuelos y jóvenes. Asimismo los rituales propiciatorios se realizan en ellos. Apreciamos, también, cómo son percibidos estos antepasados. Imagen que corresponde también a la representación de las parejas mallku-t'alla (hombremujer) en los "altares" de uywiris para la ganadería y la agricultura. Estas características, propias de los indígenas, son significadas hoy de un modo ambivalente. Por un lado, existe respeto por la exigencia que imponen las normas y valores heredados por los abuelos y, por otro, puesto que esta estética y este comportamiento no son valorados por los no indígenas, se califica como pasado, antiguo y con poca relevancia.

Bastien es uno de los autores que ha abordado la relación que los pueblos indígenas de Bolivia establecen entre el cuerpo humano y la organización del espacio geográfico y social. En su estudio sobre los kallawayas, grupo étnico de la zona mediooeste de Bolivia, describe cómo estos pobladores de la montaña nombran a sus lugares según la anatomía del cuerpo humano. La montaña es como un organismo, un cuerpo, las partes están unidas orgánicamente (cabeza, entrañas-corazón y las piernas). Estas partes representan a la vez los tres ayllus exógamos residentes. Propone que el cuerpo (nqhuntín) en esta etnia es entendido como todas aquellas partes que forman un mismo interior, incluyendo el yo interior, y las experiencias no son percibidas dualmente como aquéllas de la mente y aquéllas del cuerpo. Se refieren a su cuerpo como 
dentro e interior $(u q h u)$. La parte más importante es el corazón que bombea la sangre a través del cuerpo. El corazón es el pensamiento, las intenciones y las emociones. La sangre y la grasa dan poder al cuerpo y se produce en las entrañas. Estas incluyen el hígado, riñones, estómago e intestinos. La sangre es el principio de la vida y viene del corazón; la grasa el principio de la energía y viene de las entrañas (Bastien 1996).

Es significativo que la lengua aymara actual no registre el término cuerpo. Se encuentra una aymarización de la palabra en español (kurpu). No obstante, el cuerpo (de animal) y, por lo tanto, humano, también se encuentra en la simbolización de los tejidos de Isluga, comunidad del altiplano chileno. Cereceda sugiere que las telas se organizan espacialmente de manera simétrica en dos mitades, nombradas como cuerpos con un centro que recibe el nombre de corazón (chhima); asociación que simbolizaría a la vez la organización social dual de la comunidad. Arajj saya (mitad de arriba) y manqha saya (mitad de abajo), concebidas como masculina y femenina cuyo centro remitiría al pueblo central o marka (Cereceda 1978).

Entre los aymara de Tarapacá, el desarrollo del ciclo vital de las personas es concebido según las capacidades-habilidades del cuerpo humano en crecimiento y en términos cíclicos: nacimiento-desarrollo (según fases cultivadas socialmente) madurez-muerte-nacimiento. La familia, grupo de parientes y la comunidad étnica son las instituciones que imponen un sistema normativo que guía este desarrollo. Este último distingue, según oposiciones binarias, el comportamiento de hombres y mujeres y lo que es femenino y masculino. La terminología empleada a cada una de estas fases nos habla de una concepción mucho más elaborada que la existente entre la población chilena mestiza (ver Carrasco 1999).

La fase de transición más importante es el matrimonio, momento en el que los individuos se hacen personas (jaqi). ${ }^{10}$ Ser persona social, implica un nuevo proceso de socialización de valores y nor-

10 La importancia de esta transición se puede observar en el rito de pasaje que se manifiesta en la casarata o ceremonia de matrimonio. Aun cuando las sofisticadas ceremonias de antaño se han reemplazado por nuevas formas (orientadas por la Iglesia Protestante o Católica), sigue siendo de gran importancia en la vida de mujeres y hombres de origen indígena. mas sociales. Los recién casados son neófitos, desconocedores de la vida en pareja y de la vida socioeconómica y sociopolítica.

Existe la creencia que las personas van elaborándose a través de un proceso, pasando etapas "decorosamente", lo cual es posible mediante la formación del "corazón". En términos aymara: las personas tienen corazón o no. Un niño pequeño tiene poco corazón, está recién formándose, biológica y socialmente. Cuando se adquiere el estatus de esposa/esposo comienza el desarrollo del verdadero "corazón". De aquí el ritual del matrimonio (casarata) en el que a los recién casados se les llama "guaguas" (bebés). Prontamente van tomando las riendas de su vida y realizando acciones que les permiten ganarse el respeto y prestigio del grupo.

La persona con mayor prestigio es aquella que cumple con su familia y comunidad en términos económicos y sociales (pasantías de santos patronos y carnavales), hasta llegar a la ancianidad. Un abuelo que ha cumplido correctamente a lo largo de su vida con el ideal de un comunero tiene "corazón" y exitosamente cultivado.

Estas ideas acerca del desarrollo de la humanidad pueden ser observadas en los funerales. Si la persona fallecida es poseedora de un corazón cultivado socialmente, el ritual y ajuar funerario será con todos los honores al alcance de su familia, es decir, sofisticado. En el extremo opuesto, un neonato, un bebé o algún adulto que rompa las normas de la convivencia humana, o sea, aquellos que no tienen "corazón" tendrán un funeral pobre y sin importancia.

Bertonio registró algunas ideas relacionadas con lo anterior. Por ejemplo, hallamos el término manqhue chuyma que designaría "lo interior del corazón o pensamiento" (Bertonio 1984 [1612]: 215). Esta parte del cuerpo es esencial en la construcción del sujeto, pues en tanto pensamiento se precisa elaborar, formar. Esto coincidiría con lo señalado por Bastien respecto a que su función para la vida es clave para la reproducción del individuo y la sociedad. Se trataría de la emoción y la razón. Entre los aymara del norte chileno encontramos que la cabeza es la parte que se forma primero en el feto masculino, las manos y las piernas en el femenino. Si consideramos que "cabeza" en las lenguas latinas es una parte capital del individuo, puesto que se distingue como sede del pensamiento y la parte superior del cuerpo, lo que deriva en la noción de mando (Guiraud 2001 [1980]), tendríamos 
que asumir que los hombres y lo masculino se marcan en este sentido. No obstante, la importancia asignada al corazón pervive como lugar del centro motor de la vida, por lo que tanto mujeres como hombres están dotados de este órgano.

Esta noción de corazón (entrañas) como eje central del organismo (de un cuerpo=territorio o sujeto) se halla, entonces, en la organización social de la comunidad (manqha saya y arajj saya) con un centro (taypi o medio) que las une y, en la textilería, que en la expresión chhima recibe la marca del adentro y profundo: de las entrañas.

El adentro recibe una importancia crucial para la vida cotidiana y también para la trascendente. De aquí emerge la vida y la muerte, confluye el tiempo y el espacio. El adentro (interior) en el cuerpo humano correspondería a las entrañas, cuyo componente central es el corazón. En este sentido, Bertonio también nos señala que la expresión hanchini se usó para referirse a cuerpo con su alma (un individuo integrado) (Bertonio 1984 [1612]: 118). ${ }^{11}$

La oposición masculino/femenino se halla en el centro del pensamiento aymara. Las nociones espacio/tiempo, las divinidades y, por lo tanto, los rituales se organizan simbólicamente en torno a esta dualidad. La naturaleza del cuerpo humano femenino y masculino entre los Macha, Bolivia, está dada por dos tipos diferentes de sangre: roja y blanca. Mientras los hombres poseen en mayor cantidad la blanca, las mujeres, la roja. Si bien ambos tienen úteros, los primeros son pequeños, las segundas grandes. Así, la concepción de un nuevo ser humano es posible por la combinación de ambos tipos de sangre (Platt 2001).

El semen del hombre es una forma complementaria de la sangre en la concepción. De acuerdo a este autor, el ciclo menstrual de las mujeres estaría asociado con el ciclo lunar y sería el período de la luna nueva y llena el que se considera de extrema fertilidad. La vida debe ser impulsada si el inicio de la coagulación germina. Esta vitalidad estaría dada por una fuerza sobrenatural asociada a las divinidades de la Tierra. La capacidad de una mujer para concebir está asociada con su piedra fértil local o camiri. Sería a través de ésta que la energía vital entra en la matriz de la mujer, conjunta la sangre de ambos padres torciendo, dentro, la coagula-

\footnotetext{
11 Hanchini, que tiene cuerpo y alma o alma con el cuerpo.
}

ción. Vida, desde esta perspectiva, sería nacer del fondo de la tierra desde el manqha saya, de adentro, de las profundidades de la tierra: lugar en el que habitan los "demonios" femeninos y masculinos. La asociación de estos demonios con la regeneración y crecimiento se muestran también en los rituales a los aviadores (supay), nombre dado por los cristianos al alma de los ancestros muertos. Así, el autor infiere que la chispa de la vida de las nuevas formas de fetos es un alma ancestral transmitida como emanación petrificada de un camiri y entonces se reencarna en una nueva vida que formó la matriz como resultado del cruzamiento de la coagulación producto de ambas substancias (Platt 2001).

Las mujeres aymara del altiplano chileno postulan asimismo que la fase final del período menstrual es el momento más fértil de la mujer:

"cuando uno se abre, cuando menstruación, entonces antes que se cierre eso, cuando tiene relaciones, ahí queda embarazada. Cuando estamos con hombre ahí se cría la guagua, en la mensual, ahí cae la guagua. Cuando perdiendo tu mensual al tercer o cuarto día ahí vas a tener. Según gente también es. Los hombres y las mujeres hay que tener, el hombre agarra sueño no más. En ese agarra, cuando nosotros estamos echando cobaja a la leche pa' hacer queso, asimismo agarra la guagua, asimismo pesca, como dos semanas, un mes, así está como bolita en un rinconcito, clarito está. Cuando toca jiyau; dice."

Para algunas mujeres residentes en la ciudad, la parte más importante del cuerpo femenino sería el vientre, especialmente dentro de él la matriz, la cual debe cuidarse, ya que si ésta se enferma peligra la gestación de los hijos. Por otro lado, la parte más importante del cuerpo del hombre serían sus órganos genitales.

En la base del sistema cognitivo de la población aymara se halla su experiencia campesina, en la que la ganadería constituye una fuente importante de conocimiento biológico, lo que ha ido siendo reemplazado por los cursos impartidos por el sistema educacional. ${ }^{12}$

\footnotetext{
12 En un estudio empírico realizado en los últimos tres años en grupos urbanos y rurales, mujeres y hombres, con distintos niveles de escolaridad, encontramos que a mayor escolaridad mayor separación entre religiosidad y biología corporal y, por lo tanto, mayor semejanza con los grupos no indígenas.
} 
De este modo, las diferencias de los cuerpos diferenciados y clasificados como hembra-macho (mujer-hombre), constituyen la materia prima para elaborar la valencia diferencial de los géneros.

La gran importancia que adquiere la matriz (útero) en términos simbólicos, figura que es reiterada para comprender las capacidades de Pachamama (deidad femenina central) de contención, nutrición y generadora de "la vida" en este mundo, habla del valor asignado a lo femenino. Asimismo, la sangre (lo rojo: wila), elemento constitutivo de la vida y, por lo tanto, alimento apreciado por la deidades (pasado) conducen a situar a la sangre menstrual en un lugar central en la reproducción del grupo étnico. ${ }^{13}$ Esta asociación lleva a que las mujeres sean parte fundamental de la producción y reproducción del hogar. La norma señala que las mujeres deben ser proveedoras del hogar, tanto como los hombres; norma que se distingue del sistema normativo que imperó entre los grupos mestizos del país por largas décadas. Al parecer, el sistema normativo que orienta la sexualidad femenina no la opone a la maternidad; ambas forman parte de la esencia femenina, arquitectura que se observa en la concepción de la vida de las divinidades, quienes mantienen una vida sexual a semejanza de la humanidad del presente.

La grasa y el semen (lo blanco: hanko), elementos asociados a lo masculino, determinan esencialmente el ser masculino. Los provee, por tanto, de herramientas para vitalizar el cuerpo y la vida social. Lik'ichiri, es el término aymara para designar al personaje mítico que extrae la grasa a los vivos por efectos mágicos. Al hacerlo, la energía vital se agota hasta la muerte. Justamente la grasa es un componente central en los rituales, junto con la sangre. Del mismo modo, la presencia del hombre-esposo y su trabajo en el hogar completa la otra parte necesaria para su reproducción.

Estas ideas sostienen la distribución diferencial de tareas, responsabilidades y poder entre los sexosgéneros. En consecuencia, se podría asumir que el lugar de lo masculino y su posición de poder (expresada en los términos esposo-padre) supondrían un mayor valor a estos atributos fisiológicos del cuerpo del hombre.

13 Wilancha es el nombre que recibe el sacrificio ritual, ofrenda a las deidades principales.

\section{Tres: Aproximaciones a una proxemia aymara}

Mauss denominó a los usos que se hacen del cuerpo "técnicas corporales", las que son modeladas por la sociedad mediante la socialización concertada o vía la imitación espontánea. Para estudiar mejor las técnicas corporales, propone tener presente una visión sincrónica, para referirse a los mecanismos que orientan los cuerpos en un mismo momento, y otra diacrónica, referida a los cambios de los mismos a lo largo de su vida (Mauss 1973, cit. en García 2004).

La nominación de técnicas sigue la idea utilitarista de concebir las prácticas corporales como un medio de la sociedad para controlar los cuerpos de los sujetos. Aun cuando esta tesis puede orientar el trabajo empírico, aquí optamos por la propuesta lingüística de la proxemia por dos motivos. Por un lado, ésta ofrece un marco de mayor flexibilidad que puede recuperar el dinamismo que posee el lenguaje. Y, por el otro, dado el carácter exploratorio de los datos obtenidos.

Guiraud (2001 [1980]) sugiere que la proxemia o estudio de las posiciones y desplazamientos del cuerpo corresponde a lo que se podría llamar el lenguaje del cuerpo, un sistema explícitamente arbitrario y convencional, y operaría a un nivel inconsciente.

Si bien proxemia entre los aymara o el descubrimiento de la gramática que rige el lenguaje de los cuerpos requeriría un estudio en profundidad, podemos adelantar algo a fin de identificar algunos elementos que se vinculan con la identidad étnica y de género. Antes, es útil considerar algunos aspectos de la estética indígena que imperaban en las comunidades altiplánicas en la década de los $80 .{ }^{14}$

Un cuerpo femenino altamente valorado, era aquel que no es delgado y con una cintura ancha. Un rostro redondo con ojos que se extravían constituye un modelo ideal. Un cuerpo masculino valorado es el firme y fuerte, con brazos y piernas bien constituidas y espalda amplia. El color de la piel más clara es también un signo de belleza. El peinado y el vestido son un signo de distinción. El pelo largo

\footnotetext{
14 Me refiero al trabajo de campo realizado en las comunida-
} des de Isluga y Cariquima, entre los años 1980 y 1983. 
que puede trenzarse, el número de trenzas y los accesorios para el cabello que puedan sujetarlo alrededor de la cara es lo mejor y hace bellas a las mujeres. El vestido, ya sea el akso (tejido por ellas mismas) o la ropa comprada, tiene una forma particular de caer sobre el cuerpo y cubrirlo de manera decente, abrigar o embellecer. El sombrero y su posición son importantes. Si éste se encuentra cargado hacia un lado, es signo de una coquetería sancionada socialmente por las propias mujeres. El rebozo o chal que cubre desde la cabeza hacia las piernas es un elemento especialmente femenino, con el que se cubre el rostro, dejando casi la mitad para mirar de lado o hacia abajo. De frente es violento. Forma que recuerda a "Las Tapadas" que pintó Rugendas en Lima. La mayor parte del cuerpo debe estar cubierta. Sin embargo, se cuidan de manera especial los genitales. Los senos que amamantan se exponen sin pudor y no constituyen un objeto erótico. La sangre menstrual, en esos años, se ocultaba en la mayoría de las mujeres, especialmente las más jóvenes; mientras que para algunas el flujo formaba parte de la naturaleza del cuerpo femenino, lo cual es conocido por toda la población y en consecuencia no era necesario su ocultamiento. Asimismo, orinar y defecar era un acto público, incluso en los baños recientemente instalados por el municipio o la escuela.

Uno de los aspectos que llama la atención al foráneo es la drástica diferencia entre mujeres y hombres a la hora del descanso, particularmente, en la forma de sentarse. Los hombres pueden hacerlo en sillas y tirarse de forma extendida en el suelo. Las mujeres, con las piernas hacia un lado sobre la tierra, siempre en contacto con la tierra. En todos los rituales, los hombres se ubicarán a la derecha, mientras que las mujeres a la izquierda. Llamará la atención también el modo de caminar, de forma rápida y a pasos cortos, los hombres delante y las mujeres atrás.

Un cuerpo que muestra el trabajo que se ha desarrollado a lo largo de la vida es altamente valorado. Mientras para las mujeres el cuerpo cansado es notorio en la actividad textil, el pastoreo y la agricultura, los hombres lo notan en la actividad agrícola y el pastoreo. Caminar por el campo, desplazándose de un pueblo a otro es una actividad común entre los más ancianos en Isluga.

Las reglas de cortesía imponen saludar con la mano, sólo con un suave roce y, en ocasiones especiales, un abrazo que no toque de frente los cuerpos, y sin golpes.

Las mujeres cargan sobre sus espaldas a sus hijos, leña u otros objetos. Los hombres nunca cargarán a los niños, sólo objetos. El beneficio de la quínoa, lo que supone pisarla con los pies apenas tostada para sacar su cáscara, sólo es realizada por mujeres, nunca lo hacen los hombres. Si alguien transgrede estas reglas, provoca risa y hace el ridículo, pues ven a cuerpos no aptos para estas tareas.

Todos estos aspectos, considerados como formas correctas de comportarse, configuran un cuadro de referencia para designar a quienes no lo siguen como carente de normas y valores humanos. El q'ara, justamente es aquel que se halla lejos de estas pautas. La diferencia es calificada tanto para hombres como para mujeres. Los modelos femeninos y masculinos se elaboran y reelaboran a nivel de las representaciones, considerando la historia oral, adaptándola al contexto y la situación. Así, podríamos señalar que la proxemia aymara, aquella que orienta el lenguaje de los cuerpos femeninos y masculinos, se distingue hoy de la proxemia no indígena en la región. A pesar de que probablemente muchos de los comportamientos ideales correspondan a modelos instalados por la cultura colonial medieval no indígena, mujeres y hombres de origen indígena tenderán a cultivar cuerpos según una ideología basada en diferencias esenciales entre los cuerpos sexuados; la que se sostiene en la convicción de reglas y valores heredados de un pasado propio. Habría que agregar que tanto la población de origen indígena como la no indígena no son homogéneas en su interior. Las clases sociales intervienen de manera decisiva, lo cual incide en la mayor o menor escolarización; y es la escuela el medio principal de cambio en los procesos de aculturación que vive la población aymara (ver Nota 12).

\section{Reflexiones finales}

Lo expuesto muestra que la forma de representar los cuerpos y los sexos, así como las diferencias sexuales, configura un saber acerca de la biología animal. La no separación entre los dominios religiosos y biológicos y la forma de elaborar la relación entre cuerpos sexuados y representaciones simbólicas de los mismos, ofrecen una constelación de conocimientos que justifican las prácticas de mujeres y hombres y permiten asignarles valores diferenciados. 
El cuerpo es el primer material del que dispone el sujeto para elaborar su identidad. Por imitación y por socialización éste va desarrollándose bajo ideas y mecanismos que le provee su grupo cultural para distinguirse de otros cuerpos. Estas ideas y estos mecanismos son compartidos, en términos generales, por la colectividad étnica, que dista de ser homogénea. El género y la generación, tanto como las clases sociales, determinan su heterogeneidad.

La investigación empírica nos señala, sin embargo, que las variaciones en las representaciones de la naturaleza del cuerpo humano se dan principalmente según generación y el grado de intervención de la familia campesina en la socialización de la persona; siendo este último el factor más importante. La intervención de la escuela, tiende a marcar la separación entre biología y religiosidad. Entre la población con menor incidencia escolar y mayor experiencia campesina, independientemente de su edad y residencia urbana o rural, está presente la idea que los cuerpos humanos y de los animales sexuados sirven de base a la representación del paisaje. En primer lugar, se halla la división sexual y generacional sobre la cual se erigen distinciones binarias que determinan el funcionamiento del individuo. De la observación de las diferencias y semejanzas anatómicas y fisiológicas se desprenden nociones abstractas que jerarquizan la realidad; jerarquización que opera bajo el código de la ideología religiosa.

Los cuerpos y su fisiología se piensan como parte de la naturaleza organizada por entidades tutelares que dirigen el destino de los habitantes. La grasa y la sangre serían los elementos básicos del funcionamiento corporal, fluidos presentes en todos los rituales conocidos. Los cuerpos son "naturalmente" diferentes, lo que permite construir al género femenino y masculino a mujeres y hombres y sus relaciones.

La reproducción biológica y social del individuo se entiende del mismo modo que la reproducción del grupo doméstico y su comunidad. Se requiere de dos partes: lo femenino y lo masculino, cuya unidad social y sexual realiza la reproducción. En el nivel del hogar, la relación esposo-esposa lleva adelante su reproducción, mediante su trabajo compartido en la sexualidad, en lo laboral y en lo social. En el nivel de la comunidad, la organización social manqha saya (femenino) y arajj saya (masculino) y sus relaciones a través de intercambios matrimoniales y simbolizado en un conjunto de rituales referidos a la unidad sexual.

Se recurre así a la reproducción sexual de los cuerpos diferenciados para comprender distintos dominios de la realidad social. Significar a la organización social y espacial de la comunidad, a la cosmogonía y a los seres tutelares bajo los signos de femenino y masculino, implica un recurso reiterativo para marcar las diferencias sexuales como el centro de la dinámica social.

Estas ideas se hallan en el centro de la identidad simbólica del pueblo indio. El conocimiento acerca del cuerpo animal $-\mathrm{y}$, por ende, humano- y del paisaje de la región ha sido heredado de generaciones anteriores que no pertenecen al no indígena. De aquí la convicción de la diferencia histórico-cultural respecto del hombre y la mujer no indígena. Esto nos ayuda a entender cómo el desconocimiento de los lugares "fuertes", esto es, aquellos que provienen de las entrañas de la Pachamama como Sereno, uywiri de la música, en su forma femenina puede afectar a un joven al punto de su muerte. Esta situación ocurrió recientemente, a inicios de 2005. El deseo sexual de "esta demonia", imaginada con hambre de sangre y grasa, es activado en la temporada de visita de los antepasados (verano) por la incursión de un joven que desconoce las reglas de comportamiento. Ello, hasta devorarlo; mientras los médicos del servicio de salud no pueden explicar el estado de este cuerpo afectado.

Estos antecedentes exponen, también, la importancia que adquiere la categoría "adentro" en el sistema clasificatorio indígena. Adquiriría mayor relevancia que el arriba y el abajo. El adentro, como las entrañas, el útero contenedor (imagen de la Pachamama) siguiendo la idea de G. Martínez (1989), representa la esencia de la humanidad pensada bajo dos formas: hembra/macho. De aquí, tal vez, la importancia de los fetos (suyus) animales, nonatos. El esfuerzo por mantener con vida a los nonatos de llamas y alpacas y guardarlos sin vida para efectos rituales es notable hasta hoy.

Estas representaciones se inscriben en un legado histórico: el de los antepasados. Las narrativas de origen que aún persisten en la memoria del pueblo aymara son la base fundamental de los argumentos de la diferencia; es decir, lo que les lleva a mantener la frontera étnica. En este sentido, es posible que en el centro de esta trama se ubique el Inka. La 
referencia al Inka como símbolo del sujeto de origen indígena es reiterada para distinguirse del q'ara. Los no indígenas no poseen este pasado y, por lo tanto, no disponen de un sistema normativo y valórico que éste les legó. El Inka como emblema no es el Estado/Iglesia prehispánico reconstruido por los historiadores, es el pasado representado mediante la forma de figura humana y con capacidades sobrenaturales, protectora y vigilante del presente; y aun cuando esté impregnado por códigos cristianos, se cree procedente de un origen no $Q^{\prime}$ ara. Es decir, un cuerpo cuyo centro motor (corazón o entrañas) le permite la regeneración cíclica que salvará al pueblo indio. Una convicción que auspicia la cohesión cultural de un grupo social marginal y estigmatizado por largos siglos, más no necesariamente social. La creencia de un origen común que normativiza la convivencia no es suficiente para hacer frente al proceso de diferenciación social y, por tanto, de desigualdad social; se requiere mucho más que eso para la integración social. Se requiere de demandas y propuestas ante el Estado-nación y los otros grupos de la sociedad civil. Pero para su elaboración sirve esencializar la diferencia a fin de instalar la identidad étnica por sobre las otras dimensiones de la identidad y así eclipsar, de manera principal, la identidad de género y de clase. En esta línea vale la pena recordar la representación que las dirigentes indígenas hacen de las relaciones entre hombres y mujeres en términos de complementariedad. Una cosa es que las relaciones sean culturalmente diferentes a otros grupos, y otra muy diferente, que la complementariedad implique igualdad social entre los géneros.
Finalmente, se podría agregar que este material informativo apunta a un cierto distanciamiento de la teoría de la desintegración o de pérdida cultural. Estos conceptos no nos sirven para observar los procesos de transformación cultural. Ciertamente la intervención del sistema escolar, instrumento del Estado para impulsar el proceso de modernización, ha sido el principal mecanismo para provocar los cambios culturales, pero desconocemos cómo la población de origen indígena se relaciona con las nuevas ideologías. Si pensamos en éstos como agentes sociales, deberíamos asumir que la negociación y adaptación crítica de la cultura hegemónica conducen a nuevas formas de sentir, pensar y actuar. Los procesos de interacción darían cuenta de procesos de resignificación de los contenidos culturales que orientan las prácticas andinas.

Habría que reconocer que, como la población no indígena, los aymara siguen un proyecto de modernización que se orienta cada vez más a un proceso de secularización que tiende a separar la biología de la religión, pero no habría que olvidar que la biología no se encuentra excluida de la cultura, sino que está dentro de ella y lo que habría que distinguir es la biología y medicina como sistema de conocimiento científico, y la biología como sistema de conocimiento arraigado en el sentido común de los diferentes grupos sociales.

En este sentido, es importante reconocer ritmos de transformación que ocurren con la modernización en los distintos planos. La economía se transforma a pasos más acelerados que las representaciones del cuerpo, no obstante la voluntad de distinción con el q'ara se mantiene.

\section{REFERENCIAS CITADAS}

BASTIEN, J., 1996. La montaña y el cóndor. Hisbol, La Paz.

BERTONIO, L., 1984 [1612]. Vocabulario de la Lengua Aymara. CERES, IFEA, MUSEF, Cochabamba.

BOURDIEU, P., 1991. La creencia y el cuerpo. En El sentido práctico. Pp. 113-136. Taurus Ediciones, Madrid.

CARRASCO, A. M., 1999. Constitución de género y ciclo vital entre los aymara contemporáneos. Chungara 30 (1): 187-103.

CERECEDA, V., 1978. Semiologie des tissus andins: Les talegas d'Isluga. Annales 33 (5-6): 1017-1035.
CHIPANA, C., 1986. La identidad étnica de los aymara en Arica. Chungara 16/17: 251-261.

D'ANDREA, D., 2000. Las razones de la etnicidad entre globalización y eclipse de la política. En Identità e conflitti, F. Cerutti y D. D'Andrea (Eds), pp. 83-91. Franco Angeli, Milán.

DOUGLAS, M., 1979. "Do dogs laugh". A cross cultural approach to body symbolism. En Implicit meanings: Essays in anthropology, M. Douglas (Comp.), pp. 165170. Routledge, Londres. 
DURKHEIM, E. y M. MAUSS, 1991 [1903]. De ciertas formas primitivas de clasificación. Contribución al estudio de las representaciones colectivas. En Institución y culto obras II, Barral Editores, Madrid.

FOUCAULT, M., 1980. La microfísica del poder. La Piqueta, Madrid.

_ 1995. Historia de la sexualidad. Siglo XXI, Madrid.

GARCIA, J. 2004. El cuerpo como cultura. En http:// www.virtual.unal.edu.co/cursos/sedes/manizales/4050041/ index.html

GIMENEZ, G., 2000a. Etnia, estado de la cuestión. En Los retos de la etnicidad en los Estados-nación del siglo XXI, L. Reyna (Comp.), pp. 45-70. CIESAS, México D. F.

2000b. Materiales para una teoría de las identidades sociales. En Decadencia y auge de las identidades, J. M. Valenzuela (Ed.), pp. 45-78. El Colegio de la Frontera Norte. Plaza y Valdés, México D. F.

GONZALEZ, H. y V. GAVILAN, 1992. Cultura e identidad aymara en el norte de Chile. Chungara 25: 143-158.

GONZALEZ, H., 1997. Apuntes sobre el tema de la identidad cultural en la Región de Tarapacá. Estudios Atacameños 13: 27-45.

-2000. Identidad cultural aymara, nacionalidad y globalización. En ¿Hay patria que defender?, S. Micco y E. Saffirio (Eds.), pp. 263-286. Centro de Estudios para el Desarrollo, Santiago.

GUIRAUD, 2001 [1980]. El lenguaje del cuerpo. Fondo de Cultura Económica, México D. F.

GUNDERMANN, H., 2001. Comunidad sociedad andina y procesos sociohistóricos en el norte de Chile. Tesis para obtener el grado de Doctor en Ciencias Sociales con Especialidad en Sociología. El Colegio de México, México D. F.

-2001 Ms. Comunidad aymara. Proceso de cambio social. Ponencia presentada en el IV Congreso de Antropología, Santiago.

GREBE, M. E., 1986. Migración, identidad y cultura aymara: Puntos de vista del actor Chungara 16/17: 251-261.
HERVIEU-LEGER, D., 1993. La religión pour memoire. Cerf, París.

KEYES, C., 2000. Etnicidad, grupos étnicos. En Diccionario de Antropología, T. Barfield (Ed.), pp. 203-206. Siglo XXI, Madrid.

OOMMEN, T. K., 1994. Raza, etnicidad y clase: Análisis de las interrelaciones. Revista Internacional de Ciencias Sociales 1 (39): 101-113.

LAMAS, M., 2002. Cuerpo: Diferencia sexual y género. Editorial Taurus, México D. F.

MALUENDA, M. y P. VALENZUELA, 2004. Símbolos y ceremonias aymaras en las relaciones con el Estado. Tesis de Licenciatura en Sociología, Universidad Arturo Prat, Iquique.

MARTINEZ, A., 2004. La construcción social del cuerpo en las sociedades contemporáneas. Papers 73 Universidad de A. Coruña. Departamento de Sociología y Ciencia Política y de la Administración, Barcelona.

MARTINEZ, G., 1989. El sistema de los uywiris en Isluga. En Espacio y pensamiento. I., pp. 109-148. Hisbol, La Paz.

MAUSS, M., 1991 [1903]. Institución y culto obras II, Barral Editores, Madrid.

PLATT, T., 2001. El feto agresivo. Parto, formación de la persona y mito-historia en los Andes. Estudios Atacameños 22: 127-155.

TUDELA, P., 1992. Transformación religiosa y desintegración de la comunidad aymara tradicional en el norte de Chile. Editorial Holos, Berlín.

TURNER, V., 1989. El cuerpo y la sociedad: Exploraciones en la teoría social. Fondo de Cultura Económica, México D. F.

1994. Avances recientes en la teoría del cuerpo. Revista de Investigaciones Sociológicas 68: 11-40.

VAN KESSEL, J., 1996. Los aymara contemporáneos de Chile. En Etnografía. Sociedades indígenas contemporáneas y su ideología, J. Hidalgo, V. Schiappacasse, H. Niemeyer, C. Aldunate y P. Mege (Eds.), pp. 47-68. Editorial Andrés Bello, Santiago. 